Informal Logic

\title{
The Distinction Between False Dilemma and False Disjunctive Syllogism
}

Taeda Tomic

Volume 41, numéro 4, 2021

URI : https://id.erudit.org/iderudit/1084846ar

DOI : https://doi.org/10.22329/il.v41i4.6233

Aller au sommaire du numéro

\section{Éditeur(s)}

Informal Logic

\section{ISSN}

0824-2577 (imprimé)

2293-734X (numérique)

Découvrir la revue

Citer cet article

Tomic, T. (2021). The Distinction Between False Dilemma and False Disjunctive Syllogism. Informal Logic, 41(4), 607-639. https://doi.org/10.22329/il.v41i4.6233
Résumé de l'article

Puisqu'un compte rendu clair du syllogisme disjonctif fallacieux est absent dans la littérature, je définis cette erreur et différencie ses trois types. La section 4 décrit en plus de détails les différences spécifiques pour chacun de ces trois types en analysant la critique argumentative pertinente de chacun, ainsi que les profils de dialogue associés. Après avoir défini les syllogismes disjonctifs fallacieux, il devient possible de distinguer entre un faux dilemme et un syllogisme disjonctif fallacieux: la section 5 analyse leurs similitudes (ce qui explique pourquoi ces sophismes sont souvent confondus) et la section 6 explique leurs différences. 


\title{
The Distinction Between False Dilemma and False Disjunctive Syllogism
}

\author{
TAEDA TOMIĆ
}

\author{
Department of Philosophy \\ Uppsala University \\ Postal Box 627 \\ 75126 Uppsala, Sweden \\ Taeda.tomic@filosofi.uu.se
}

\begin{abstract}
Since a clear account of the fallacy of false disjunctive syllogism is missing in the literature, the fallacy is defined and its three types are differentiated after some preliminaries. Section 4 further elaborates the differentia specifica for each of the three types by analyzing relevant argument criticism of each, as well as the related profiles of dialogue. After defining false disjunctive syllogisms, it becomes possible to distinguish between a false dilemma and a false disjunctive syllogism: section 5 analyzes their similarities (which explains why the fallacies are often confused with one another) and section 6 explains their differences.

Résumé: Puisqu'un compte rendu clair du syllogisme disjonctif fallacieux est absent dans la littérature, je définis cette erreur et différencie ses trois types. La section 4 décrit en plus de détails les différences spécifiques pour chacun de ces trois types en analysant la critique argumentative pertinente de chacun, ainsi que les profils de dialogue associés. Après avoir défini les syllogismes disjonctifs fallacieux, il devient possible de distinguer entre un faux dilemme et un syllogisme disjonctif fallacieux: la section 5 analyse leurs similitudes (ce qui explique pourquoi ces sophismes sont souvent confondus) et la section 6 explique leurs différences.
\end{abstract}

Keywords: analytical thinking, argument criticism, argument schemas, informal logic, false dilemma, false disjunctive syllogism, fallacies, profiles of dialogue, relevance

\section{Introduction}

In the field of informal logic and argumentation theory, there are almost no works on disjunctive fallacies. In the extensive bibliography on fallacies (Hansen and Fioret 2016), there are only two articles (Govier 2007; Tomić 2013) on the fallacy "false disjunction (dichotomy, alternatives)," as it is called in the bibliography. 
In contrast, there are 90 works (articles or books) on six different types of ad hominem fallacy in the bibliography.

While there is a systematic presentation of false dilemma (Tomic 2013), analysis of the fallacy of false disjunctive syllogism is still missing in the field. Some works contain short considerations about affirming a disjunct without placing it into fallacies or explaining how it appears to be a good argument (e.g., Copi et al. 2011, p. 273; Pospesel and Lycan 2000, p. 209), even though affirming a disjunct is only one variant of false disjunctive syllogism. Cavender and Kahane (2010, p. 58) briefly mention the "either-or fallacy" calling it a rhetorical device. However, most of the relevant works on fallacies do not consider false disjunctive syllogism (e.g., Hamblin 1970; Hansen 2020; Hansen and Pinto 1995; Johnson and Blair 1994; Tindale 2007).

Some formal-logical works analyze the validity of disjunctive syllogism (e.g., Anderson and Belnap 1975, pp. 165, 174-76; Bhave 1997; Mortensen 1983; Routley 1984). According to Anderson and Belnap (1975), disjunctive syllogism is not a tautologically valid form of reasoning because certain ways of using it contain a relevance fallacy. Anderson and Belnap's discovery, which is only a part of their lucid analysis of entailment, has been very influential in formal logic; for instance, it has initiated developments of relevance logic. Despite their clear and influential analysis, not even that type of false disjunctive syllogism is included in the contemporary literature on fallacies in informal logic and argumentation theory.

Additionally, even the distinction between false dilemma and false disjunctive syllogism is lacking in the field. A current confusion between three concepts-false dilemma, false disjunctive syllogism and false dichotomy - makes it even more difficult to differentiate between the two fallacies: false disjunctive syllogism and false dilemma. Tomić (2013) clarifies the distinction between two of the three concepts that are often confused with one another-false dilemma and false dichotomy-rightly stating that the first is a logically incorrect argument whereas the second is a false statement (even if that kind of statement is one of the premises in certain types of false dilemma). Govier (2001, pp. 234-35, 441, 2007) also points out that false dichotomy is a false belief or 
statement, and not an argument. However, in many textbooks, and other types of texts, false dichotomy, false dilemma and false disjunctive syllogism are surprisingly confused with one another and presented as one and the same type of reasoning (Bowell and Kemp 2015, pp. 254-55; van Eemeren and Grootendorst 1992, pp. 191-93; van Vleet 2010, pp. 14-15).

The aim of the present article is therefore twofold:

- to analyze and define the fallacy of false disjunctive syllogism, and

- to clarify the distinction between false dilemma and false disjunctive syllogism.

The article does not aim at an empirical analysis of all uses of either/or reasoning in natural-English. Nor does it attempt an empirical analysis of argumentative discourses containing false disjunctive syllogism. Such a study would be of great benefit, but the space of the article is limited. The article is rather about reasoning involved in the fallacy as related to the argument schema of disjunctive syllogism. This approach may make upcoming empirical studies easier as a starting-point framework, which in turn can inspire further studies of false disjunctive syllogism.

One innovation of the article is the definition of false disjunctive syllogism distinguishing between its three types in Section 3. Another new aspect is the guidelines for distinguishing between several types of the same fallacy in Section 2. The fourth section explores a general account of argument criticism and corresponding profiles of dialogue (Krabbe 1992, 1999). However, the article demonstrates a new, specific application of the analytical tools to the three types of false disjunctive syllogism, which further elaborates the differentia specifica for each of the three types. After defining false disjunctive syllogism, it becomes possible to distinguish between a false dilemma and a false disjunctive syllogism. This distinction is another new contribution of the article. Section 5 analyzes similarities between the two fallacies, which explains why the fallacies are often confused with one another. Section 6 explains their differences. 


\section{Some preliminaries}

There are at least three ways in which disjunctive syllogism may be used falsely. One is known as affirming a disjunct, the second may be titled using an irrelevant disjunction, the third may be called unsound disjunctive syllogism. It is necessary to distinguish between the three types of false disjunctive syllogism for the following reasons:

- This may improve the ability to deal with the fallacy in argumentative discourses, such as those concerning decision making, diagnostic practices, political debates or improvement of mental health (e.g. handling implicit arguments on the allegedly positive effects of excessive worry used by patients with GAD [Dugas and Robichaud 2007, pp. 124, 128]).

- Knowing their characteristics improves the ability to distinguish them from other related fallacies, i.e., false dilemma.

- Distinguishing between the three types of false disjunctive syllogism contributes to a clear analytical definition of the fallacy and thus to further systematization of fallacies in the literature of informal logic and argumentation.

- The distinction shows that some fallacies can manifest both as formal and informal fallacies.

Characteristics that distinguish the three types of false disjunctive syllogism are described generally, below. They are elaborated in Sections 3 and 4.

i) Each of the three types demonstrates a distinctive way of falsely appealing to the valid argument schemas of disjunctive syllogism, shown in Figures 2 and 3. Some of them do this by ways of formal fallacies and are nonvalid arguments. Others contain informal fallacies, i.e., irrelevance or false/incomplete premises, thus faulty argu- 
mentation, despite being truth-functionally valid arguments. This justifies the contention that different ways of reasoning are used in the three types of the fallacy. This is analyzed in Section 3.

ii) Different strategies of argument criticisms are required to deal with each of the three types of the fallacy, which also confirms the difference in the reasoning explored in them. This is analyzed in Section 4.

iii) Different profiles of dialogue are required to graphically present the structure of the corresponding argument criticisms, strengthening (ii). This is analyzed in Section 4.

iv) Different argument evaluations are applicable to each of the three types of the fallacy. This also justifies the need to differentiate between them. This is analyzed in Sections 3 and 4.

To guide the reader in what to focus on in the analyses and the examples provided in Sections 3 and 4, the guidelines and the general characteristics are summarized in Figure 1. 


\begin{tabular}{|c|c|c|c|}
\hline $\begin{array}{l}\text { The guide- } \\
\text { lines }\end{array}$ & $\begin{array}{l}\text { Affirming the } \\
\text { disjunct }\end{array}$ & $\begin{array}{l}\text { Using an irrele- } \\
\text { vant disjunction }\end{array}$ & $\begin{array}{l}\text { Unsound disjunctive } \\
\text { syllogism }\end{array}$ \\
\hline $\begin{array}{l}\text { Different false } \\
\text { appeals to the } \\
\text { argument } \\
\text { schemas of } \\
\text { disjunctive } \\
\text { syllogism }\end{array}$ & $\begin{array}{l}\text { Confusing the } \\
\text { schemas for } \\
\text { including and } \\
\text { excluding } \\
\text { disjunctive } \\
\text { syllogism, and } \\
\text { the related } \\
\text { truth- } \\
\text { functionality }\end{array}$ & $\begin{array}{l}\text { The truth- } \\
\text { functionally valid } \\
\text { schema of includ- } \\
\text { ing disjunctive } \\
\text { syllogism turns } \\
\text { into a not relevant- } \\
\text { ly valid }{ }^{1} \text { argument } \\
\text { and faulty argu- } \\
\text { mentation, due to } \\
\text { the irrelevance } \\
\text { between the } \\
\text { disjuncts }\end{array}$ & $\begin{array}{l}\text { Using the valid schemas } \\
\text { of disjunctive syllogism } \\
\text { and respecting the truth- } \\
\text { functionality of disjunc- } \\
\text { tion and with relevance } \\
\text { between the disjuncts, but } \\
\text { with false/incomplete } \\
\text { disjunctive premise }\end{array}$ \\
\hline $\begin{array}{l}\text { Different } \\
\text { strategies for } \\
\text { argument } \\
\text { criticism }\end{array}$ & $\begin{array}{l}\text { Refuting by } \\
\text { using inadmis- } \\
\text { sibility criti- } \\
\text { cism }\end{array}$ & $\begin{array}{l}\text { Questioning or } \\
\text { refuting by using } \\
\text { relevance criticism }\end{array}$ & $\begin{array}{l}\text { - Questioning or refuting } \\
\text { by using tenability criti- } \\
\text { cism } \\
\text { - Refuting by using active } \\
\text { criticism }\end{array}$ \\
\hline $\begin{array}{l}\text { Different } \\
\text { profiles of } \\
\text { dialogue for } \\
\text { the corre- } \\
\text { sponding } \\
\text { argument } \\
\text { criticisms }\end{array}$ & See Figure 5 & See Figure 6 and 7 & $\begin{array}{l}\text { - See Figures } 8 \text { and } 9 \text { (the } \\
\text { profile of dialogue for the } \\
\text { tenability criticism) } \\
\text { - See Figures } 10,11 \text { and } \\
12 \text { (the profile of dialogue } \\
\text { for the active criticism) }\end{array}$ \\
\hline $\begin{array}{l}\text { Different } \\
\text { argument } \\
\text { evaluations }\end{array}$ & $\begin{array}{l}\text { Truth- } \\
\text { functionally } \\
\text { non-valid } \\
\text { argument, due } \\
\text { to equivocation } \\
\text { and to not- } \\
\text { following the } \\
\text { truth- } \\
\text { functionality }\end{array}$ & $\begin{array}{l}\text { Truth-functionally } \\
\text { but not relevantly } \\
\text { valid argument, } \\
\text { and faulty argu- } \\
\text { mentation - due to } \\
\text { the irrelevance } \\
\text { between the } \\
\text { disjuncts }\end{array}$ & $\begin{array}{l}\text { Truth-functionally and } \\
\text { relevantly valid argument, } \\
\text { but faulty argumentation } \\
\text { due to the } \\
\text { false/incomplete disjunc- } \\
\text { tive premise }\end{array}$ \\
\hline
\end{tabular}

Figure 1: The guidelines and characteristics for distinguishing between the three types of disjunctive syllogism

${ }^{1}$ See section 3.2 


\section{False disjunctive syllogism}

One valid argument schema of disjunctive syllogism (Figure 2) has including disjunction in one of the premises, that is, a disjunctive claim in which both disjuncts can be true but cannot both be false (according to the truth conditions of including disjunction). A good example of including disjunction is the statement: "We allow immigration to the country to the same extent as now, or we help the refugees in the immediate area around the conflict hotspots (or both)."
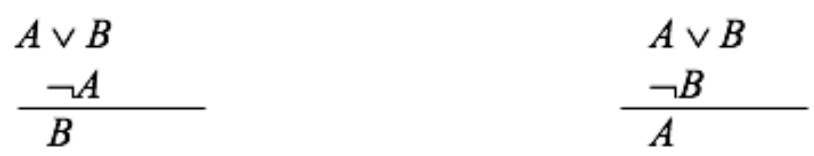

Figure 2: Argument schema of disjunctive syllogism with including disjunction

The other valid argument schema (Figure 3 ) has excluding disjunction in one of the premises, that is, a disjunctive claim in which only one of the disjuncts can be true, but not both of them, according to the truth conditions of excluding disjunction. A good example of excluding disjunction is the statement: "We either allow immigration to the country to the same extent as now, or we help the refugees in the immediate area around the conflict hotspots (but not both)."

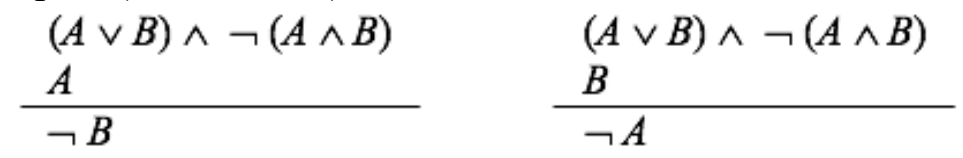

Figure 3: Argument schema of disjunctive syllogism with excluding disjunction

The different ways in which the three types of false disjunctive syllogism falsely appeal to the valid argument schemas of disjunctive syllogism show that different perspectives on defining a fallacy are applicable for each of the three types. Affirming the disjunct is a formal fallacy because it is not a truth-functionally valid argument but attempts to be. Using an irrelevant disjunction is a 
fallacy of irrelevance: it contains a truth functionally valid argument, but due to the irrelevance between the disjuncts, it turns into a not relevantly valid argument and thus also into faulty argumentation. Unsound disjunctive syllogism is an informal fallacy: it is both truth-functionally and relevantly valid argument, but the incomplete disjunctive premise with all false disjuncts turns it into faulty argumentation. In the continuance of Section 3 and in Section 4 , the differentia specifica for each of the three types is elaborated.

\subsection{Affirming a disjunct}

This type of false disjunctive syllogism is a formal fallacy: it is not a valid argument but attempts to be. It uses a logically incorrect mixture of the two valid argument schemas for disjunctive syllogism: the one with including disjunction, and the one with excluding disjunction (Figure 4). It therefore involves logically improper mixture of truth conditions for the two different types of disjunction.

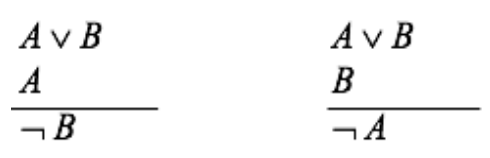

Figure 4: Argument scheme for affirming a disjunct

Even if affirming a disjunct is not a deductively valid argument, it appears to be deductively valid due to its equivocal use of the disjunctive premise. The equivocation consists of using including disjunction in the disjunctive premise but presenting it as if it were an excluding one, as shown in Figure 4 and in Example 1.

(P1) We allow immigration to the country to the same extent as now, or we help the refugees in the immediate area around the conflict hotspots.

(P2) We help the refugees in the immediate area around the conflict hotspots.

(C) We do not allow immigration to the country to the same extent as now.

\section{Example 1: An argument with affirming a disjunct}


The argument is not valid because it does not specify that the first premise would be an excluding disjunction. The premise is structurally formulated as an including disjunction because the expression "but not both" is missing, but is used as if it were excluding. Even as a matter of fact the disjuncts in the disjunctive premise both can be true - they actually do not exclude each other. Therefore, claiming one of the disjuncts does not logically imply the negation of the other one.

\subsection{Using an irrelevant disjunction}

Using an irrelevant disjunction is a fallacy of relevance. It is a truth-functionally valid argument, but the irrelevance between the disjuncts turns it into a not relevantly valid argument (where the truth-functional validity still holds). In other words, using an irrelevant disjunction respects the truth conditions of an including disjunction and is therefore a truth-functionally valid argument. Nevertheless, it presents a disjunctive syllogism with an including disjunction (Figure 2) as logically valid only due to its logical form, irrespective of the relevance between the disjuncts. However, as Anderson and Belnap have explained, a disjunctive syllogism is a relevantly valid argument only when the intensional sense of "or" is used so that there is a true relevance between the disjuncts in the claim " $A$-or- $B$ " $(1975$, pp. 166, 176). This is different from the truth-functional sense of "or" in the symbolic schema. When the intensional sense of "or" is used, the disjuncts share the propositional content which makes a disjunctive syllogism valid, as in Example 2 where the disjuncts share the propositional content of referring to the diseases with similar symptoms. Some related analyses of the concept of relevant validity may be found in Lavers (1988), and Schurz (1991). 
(P1) The symptoms indicate that it is either COVID-19 or seasonal influenza

(and if it is not the one, then it is the other).

(P2) The laboratory results confirm that it is not COVID-19.

(C) It is seasonal influenza.

Example 2: Relevantly valid disjunctive syllogism (truthfunctionally valid and with the relevance between the disjuncts) (following Anderson and Belnap 1975, p. 176).

However, when truth-functional disjunction without relevance between the disjuncts is used in the premise of disjunctive syllogism, we get using an irrelevant disjunction in which the conclusion does not logically follow from the premises, despite the argument's truth-functional validity. This is then a not relevantly valid argument (Anderson and Belnap 1975, pp. 162-67, 176-77, 296-300). This is the case in Example 3, where the disjuncts do not share the propositional content.

(P1) It is Friday today or the techniques of healthy living will be included in the curriculum.

(P2) It is not Friday today.

(C) The techniques of healthy living will be included in the curriculum.

Example 3: Using an irrelevant disjunction: disjunctive syllogism without relevance between the disjuncts

At first glance, it is not clear why anybody would accept the reasoning presented in Example 3 in any way: it is obvious that the disjuncts do not share the propositional content and that therefore the negation of one of them does not imply the assertion of the other. According to Anderson and Belnap, the reason why such an argument may still seem acceptable is the truth-functionally valid form of the argument that is usually presented as unequivocally valid, even when applied in arguments in which the intensional and not truth functional "or" is required.

It should be pointed out an additional reason why the reasoning may appear relevantly valid: the disjuncts in using an irrelevant 
disjunction may be chosen so as to seem to share propositional content, when they actually do not. In such cases, the disjuncts are not relevant to one another but people may wrongly believe that they are. This is the case in Example 4 presenting a truthfunctionally valid argument, often used by people suffering from excessive worry (following Dugas and Robichaud 2007, pp. 12628). Still, the actual argument is not relevantly valid because there is no relevance between the disjuncts: regular worry about one's performance getting wrong is in itself not relevant to the quality of the performance. However, a person who is advancing such an argument and behaving accordingly may have observed that sometimes, coincidentally, her good performance follows the worry. Therefore, and due to her intolerance of uncertainty, she wrongly believes that there is relevance between the worry and the performance - in her attempt to reduce uncertainty. One of the strategies in treatment of excessive worry is to assist clients in challenging the beliefs about a concrete worry being relevant to a concrete outcome, such as the wrong belief about the relevance between the disjuncts in (P1) (Dugas and Robichaud 2007, pp. 129-33).

(P1) I always worry beforehand that something I'm working on will get wrong, or the thing I'm working on will get wrong.

(P2) I don't always worry beforehand that something I'm working on will get wrong.

(C1) The thing I'm working on will get wrong.

Example 4: Using an irrelevant disjunction: a not relevantly valid reasoning that seems to be relevantly valid due to the seeming relevance between the disjuncts

According to Anderson and Belnap, a disjunctive syllogism with irrelevant disjunction (what is here titled using an irrelevant disjunction), makes obvious that it is not always possible to distinguish clearly between the formal fallacies (in which something is wrong with the logical form of an argument independently of its content) and the material (informal) fallacies (depending on misinterpretations, mis-presentations or omissions of the content of the 
argument). This is because the validity of the logical form of reasoning in disjunctive syllogism is dependent on the very content of the disjunctive premise and the relevance between the disjuncts (Anderson and Belnap 1975, pp. 164-65, 176-77, 236-37, 296-300).

\subsection{Unsound disjunctive syllogism}

The unsound disjunctive syllogism is an informal fallacy. It is a truth functionally and relevantly valid argument that still involves faulty argumentation due to (intentionally or unintentionally) not making obvious the falsity of the disjunctive premise and thus focusing on the argument's validity when the argument actually also attempts at soundness. The two ways in which the disjunctive premise may be false in effect amount to the same thing. All the disjuncts in the disjunctive premise may be false, which indicates that there are other, true, disjuncts of relevance; this shows that the initial premise was incomplete. On the other hand, in the incomplete disjunctive premise of the unsound disjunctive syllogism, the (seemingly) true disjuncts become obviously false when the other relevant disjuncts are included. In both ways, the disjuncts are false and the disjunctive premise is incomplete. ${ }^{2}$

In what follows, the falsity of the disjunctive premise is still approached from the two different perspectives briefly presented above. The perspective in section 3.3.1. focuses on the falsity of each of the given disjuncts; the perspective in section 3.3.2. focuses on the incomplete disjunctive premise. Describing these two different perspectives is important because it shows that the unsound disjunctive syllogism may be handled by different strategies of argument criticism and thus by different dialogue approaches discussed in Section 4.

3.3.1. The perspective with focus on the falsity of the disjuncts in the disjunctive premise

Take the unsound disjunctive syllogism with including disjunction and with relevance between the disjuncts. This truth functionally

${ }^{2}$ The author is grateful to the anonymous referee for the insight in the sentence. 
and relevantly valid argument is a fallacy due to the faulty argumentation when the argument is presented as if at least one of the disjuncts in the disjunctive premise is true in a given situation; whereas, as a matter of fact neither of them is. Examples 5 and 6 contain such reasoning.

\section{Example 5:}

(P1) We have to be materially very rich and also high performing, or we are unworthy as human beings.

(P2) We are worthy as human beings.

(C) We have to be materially very rich and also high performing.

\section{Example 6:}

(P1) We have to achieve a high social status or we have to look sexually attractive.

(P2) We do not have to look sexually attractive.

(C) We have to achieve a high social status.

In both examples, the relevance between the disjuncts, and the truth-functionality is respected, and the arguments are thus relevantly and truth-functionally valid. However, neither of the two arguments is sound, because none of the disjuncts in each of the arguments is true. That is, they all have a false disjunctive premise suggesting two options that are both, as a matter of fact, false:

- We do not have to be materially very rich and also high performing, and we are worthy as human beings.

- We do not have to achieve a high social status, and we do not have to look sexually attractive.

However, by focusing the listeners' attention only on the validity of the argument, the use of the unsound disjunctive syllogism can lead to not noticing the falsity of the disjunctive premise in the situations in which soundness is attempted; the argument may thus 
be accepted. This confusing and faulty argumentation is the reason why it is a variant of the fallacy of false disjunctive syllogism.

\subsubsection{The perspective with focus on the incomplete disjunctive premise}

Taking this perspective, the unsound disjunctive syllogism is initially presented as a sound argument: it is truth-functionally and relevantly valid, and it seemingly has all the premises factually true, but the fact that the disjunctive premise is incomplete is, intentionally or unintentionally, concealed. However, additional disjuncts (additional information) are relevant for what is considered in the argument. Due to the additional information, the initial disjuncts may all turn false and lead to another conclusion than the one in the originally given argument.

When the premise (P1) in Example 7 is presented as if it contains all the alternatives of relevance for reasoning about the conclusion, the conclusion is derived on the basis of faulty argumentation, and may be wrong, despite the truth-functional and the relevant validity of the argument.

(P1) The physician should prescribe pills or the symptoms will remain.

(P2) The symptoms will not remain.

(C1) The physician should prescribe pills.

\section{Example 7: Disjunctive syllogism with incomplete disjunctive premise}

(P2) is true given that the patient is concerned about her/his health. However, additional options are relevant for reasoning about how the physician should act if she/he wants to help the patient to get rid of the symptoms. The relevant information is thus (intentionally or unintentionally) hidden in the argument which is thus a fallacy due to the confusing and faulty argumentation. Adding relevant additional information to the first premise might refute the argument in Example 7: due to the additional information the conclusion (C1) would not have to be chosen among several possible 
conclusions (e.g., C2, C3 and C4) which would all logically follow from the augmented true premise. The refuting argument is presented in Example 8.

(P3) The physician should prescribe pills, or regular physical exercise, or regularly doing mental exercise, or a course in improvement of a new skill that the patient always wanted to learn, or coaching to diminish the patient's everyday stress, or the symptoms will remain.

(P2) The symptoms will not remain.

(P4) The physician should not prescribe pills (in the light of the new alternatives).

(C2) The physician should prescribe regular physical exercise.

(C3) The physician should prescribe a course for improvement of a new skill

that the patient always wanted to learn.

(C4) The physician should prescribe coaching to diminish the patient's everyday stress.

Example 8: An argument that refutes the unsound disjunctive syllogism in Example 7

\section{Argument criticism for false disjunctive syllogism}

This section explores a general account of argument criticism and corresponding profiles of dialogue (Krabbe 1992, 1999). However, the section demonstrates a new, specific application of the analytical tools to the three types of false disjunctive syllogism. Thus, it further elaborates the differentia specifica for each of these three types of the fallacy (described in Section 3), implements the guidelines for distinguishing them (provided in Section 2), and graphically systematizes the differences between these three types. 


\subsection{Refutation by using inadmissibility criticism}

Affirming the disjunct is best approached by refutation based on inadmissibility-criticism (Krabbe 1999, p. 10), due to equivocation. When applied to affirming the disjunct, this type of criticism points out the following:

- There is ambiguity between the including and the excluding disjunction in the disjunctive premise; and

- ambiguity makes affirming the disjunct seem to be valid when it actually is not (the conclusion does not follow from the premises, because the disjunctive premise is not excluding disjunction, neither formal-logically nor actually).

To further clarify the inadmissibility criticism, we first symbolize the main claims in the argument from Example 1 by propositional letters $\mathrm{A}$ and $\mathrm{B}$, where:

A: We allow immigration to the country to the same extent as now.

$\mathrm{B}$ : We help the refugees in the immediate area around the conflict hotspots.

We then apply the general profile of dialogue for inadmissibility criticism (Krabbe 1999) to affirming the disjunct from Example 1, as represented in Figure 5. 


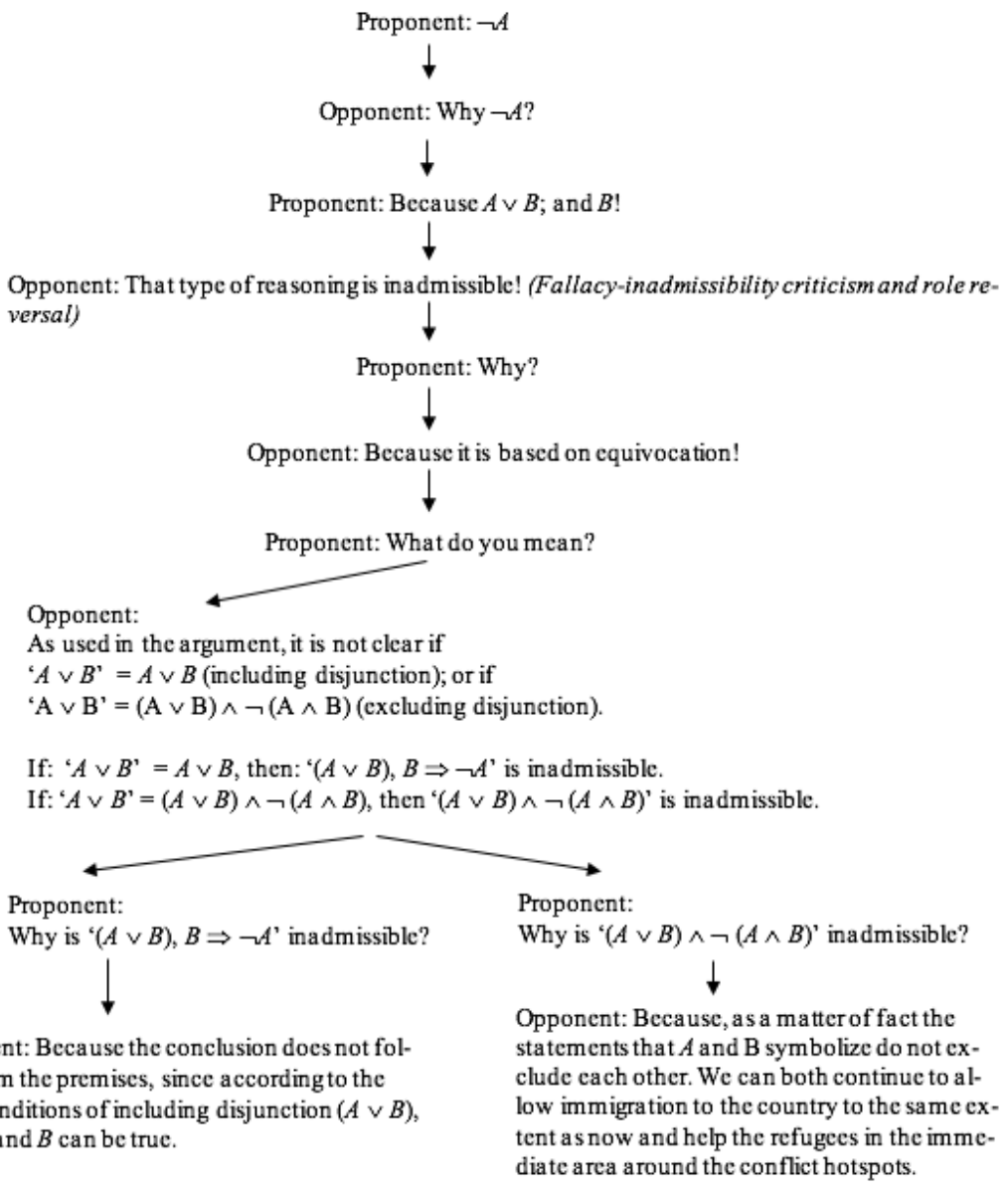

(Refutation by using inadmissibility criticism)

(Refutation by using inadmissibility criticism)

Figure 5: The profile of dialogue for inadmissibility criticism of affirming a disjunct.

Of course, refutation by using inadmissibility criticism can be expressed in a form that simply states the reasoning, without following the question-answer dialectical structure of the argumentative dialogue. However, the profile of dialogue makes the reasoning and the steps of refutation clearer. 


\subsection{Relevance criticism for using an irrelevant disjunction}

Two general types of relevance criticism, the connection criticism and the narrow-type relevance criticism (Krabbe 1992, pp. 278, $279 ; 1999$, pp. 6, 10), are the most suitable to deal with using an irrelevant disjunction. The connection criticism questions the logical connection between on the one hand the disjunctive premise with irrelevant disjuncts and the negation of one of them and, on the other hand, the conclusion. It thus asks for additional reasons for the claimed entailment between the premises and the conclusion. The narrow-type relevance criticism points out that the relevant logical connection is lacking and provides the reasons why. In other words, both types of the relevance criticism challenge the relevant validity of the advanced argument; the connection criticism asks for additional reasons to claim the validity, and the narrow-type of relevance criticism provides the reasons why the conclusion does not follow from the premises, despite the truth-functional validity of the argument. The profile of dialogue for relevance criticism (Krabbe 1992, 1999), when applied to the fallacy of using an irrelevant disjunction, makes even clearer the missing relevant validity of the argument from Example 3, as shown in figure 6 below.

Proponent : The techniques of healthy living will be included in the curriculum.

Proponent: Because it is Friday today or techniques of healthy living will be included
in the curriculum. But it is not Friday today!

Figure 6: The profile of dialogue for relevance criticism of using an irrelevant disjunction in the argument of Example 3 
Let us symbolize the simple statements from Example 3 by propositional letters $\mathrm{F}$ and $\mathrm{T}$, where

F: It is Friday today.

$\mathrm{T}$ : The techniques of healthy living will be included in the curriculum.

Then we get the general profile of dialogue for relevance criticism of using an irrelevant disjunction, as presented in Figure 7.

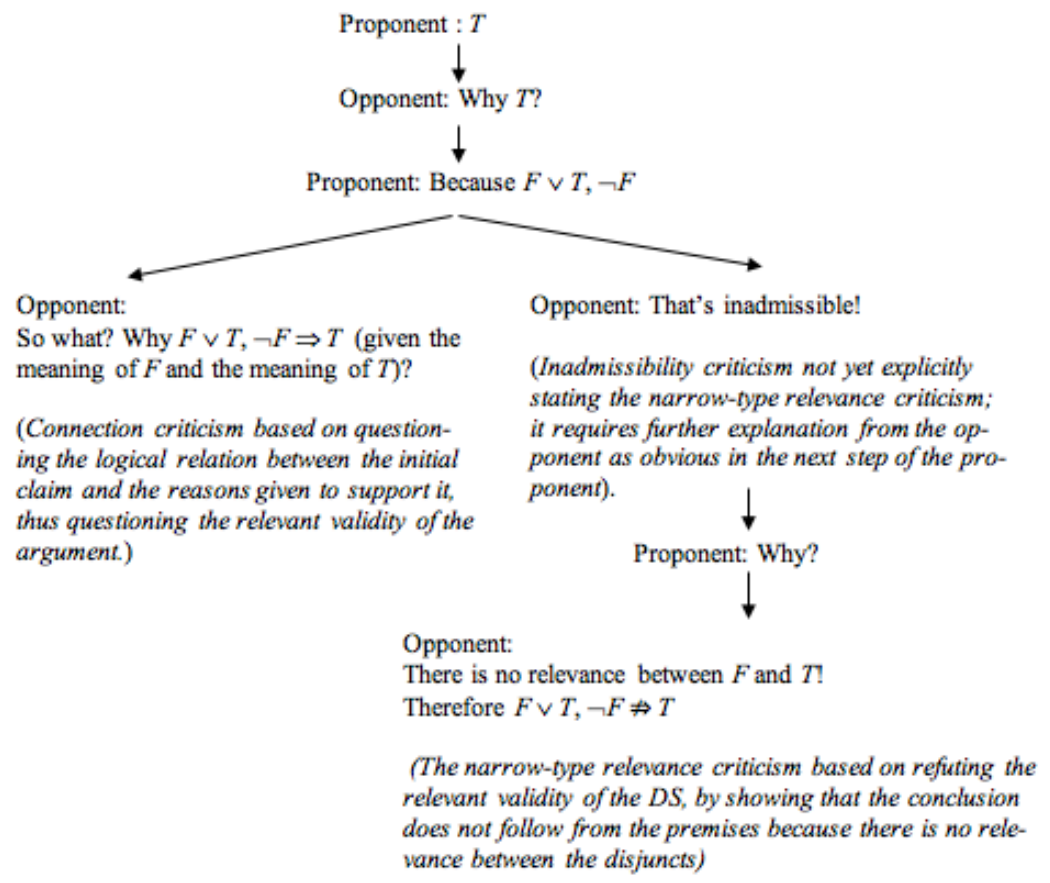

Figure 7: The profile of dialogue for relevance criticism of using an irrelevant disjunction 
4.3. Tenability criticism of unsound disjunctive syllogism with focus on the falsity of the disjuncts in the disjunctive premise

Here, the most suitable argument criticism is tenability criticism that questions the actual truth of the disjuncts, or refutes the argument by asserting the falsity of the disjuncts. This type of criticism acknowledges the truth functional and the relevant validity of the argument but points out that the argument also aims at soundness which is why the soundness of the argument is questioned or opposed.

General profile for tenability criticism (Krabbe 1999, p. 6) may suitably be applied to analyze the tenability criticism of the argument in Example 5, as shown in Figure 8 below.

Proponent : We have to be materially very rich and also high performing.

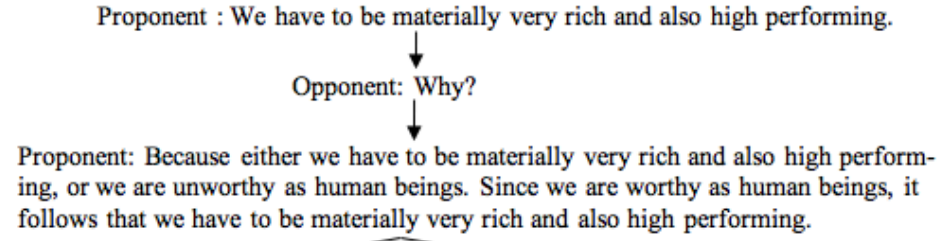

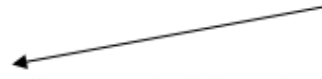

Opponent: Well, it certainly follows that we have to be materially very rich and also high performing from the reasons you give to support the claim. However, I wonder why we would assume that the reasons are also true: why is it true that we have to be materially very rich and also high performing, or we are unworthy as human beings?

(Tenability criticism based on questioning the disjuncts in the disjunctive premise and thus questioning the soundness of the argument)

\begin{abstract}
Opponent: It certainly follows that we have to be materially very rich and also high performing from the reasons you give to support the claim. However, one of the premises in the reasons you give is not true. It is not true that we have to be materially very rich and also high performing, or we are unworthy as human beings. As a matter of fact, we do not have to be materially very rich nor high performing; also, we are worthy as human beings. The argument is not sound, even if the conclusion follows from the premises.
\end{abstract}

(Tenability criticism based on opposing one of the premises by claiming that it is not true, and thus refuting the soundness of the argument).

Figure 8: The profile of dialogue for questioning and for refuting unsound disjunctive syllogism with focus on the false disjuncts in the argument from Example 5, by using tenability criticism 
Let us symbolize the simple statements used in Example 5 by propositional letters $\mathrm{M}$ and $\mathrm{W}$, where

M: We have to be materially very rich and also high performing. $\mathrm{W}$ : We are unworthy as human beings.

Then we get the general profile of dialogue for tenability criticism of unsound disjunctive syllogism with focus on the false disjuncts in the disjunctive premise, as presented in Figure 9.

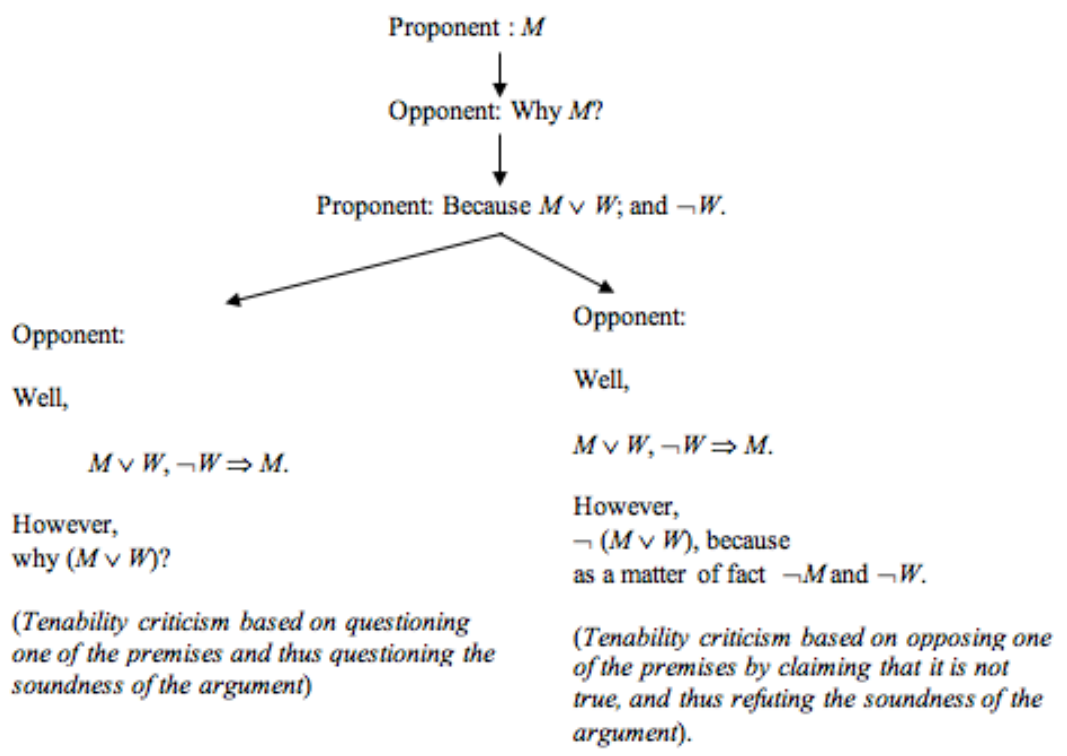

Figure 9: The profile of dialogue for tenability criticism of unsound disjunctive syllogism with focus on the false disjuncts in the disjunctive premise

4.4. Active criticism of unsound disjunctive syllogism with focus on the incomplete disjunctive premise

Here, it is best to use active criticism to show that the argument is truth functionally and relevantly valid but not all relevant disjuncts are included in the disjunctive premise. By adding the additional relevant disjuncts, both the initial disjuncts turn false and the conclusion no longer follows from the augmented set of premises.

The argument in Example 7 has an incomplete disjunctive premise because there are other alternatives of importance for the 


\section{Tomić}

reasoning. Thus, in Example 8, the disjunctive premise is augmented by additional information contained in the added disjuncts. The additional information shows that both the initial disjuncts are false, which thus refutes the conclusion of the initial argument and leads to other conclusions (e.g., (C2), (C3) and (C4) in Example 8). So, the active criticism advanced in Example 8 refutes the argument in Example 7.

This type of criticism may be analyzed by the general profile of dialogue for active criticism (Krabbe 1999, pp. 7, 10), which is presented in figure 10 with regard to the argument advanced in Example 8.

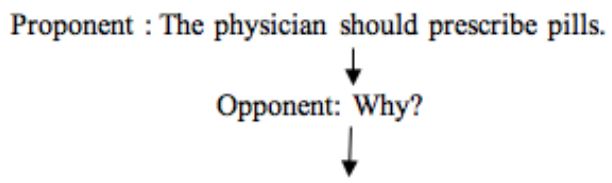

Proponent: Because the physician should prescribe pills or the symptoms will remain; but the symptoms will not remain!

\section{Opponent:}

From the two options you give, it follows that the physician should prescribe the pills. There are though other relevant options to consider:

The physician should prescribe the pills, or regular physical exercise, or doing mental exercise regularly, or a course in improvement of a new skill that the patient always wanted to learn, or coaching to diminish the patient's everyday stress, or the symptoms will remain. Now, the symptoms will not remain. And, in the light of the added alternatives, the physician should not prescribe the pills.

In this case, both the two initial options turn false and we get other conclusions (recommendations) that logically follow from the new true premises, namely:

(C2) The physician should prescribe regular physical exercise.

(C3) The physician should prescribe a course for improvement of a new skill that the patient always wanted to learn.

(C4) The physician should prescribe coaching to diminish the patient's everyday stress.

(Active criticism based on presenting new information, absent from the initial argument, that thus refutes the unsound disjunctive syllogism with incomplete disjunctive premise)

Figure 10: The profile of dialogue for active criticism of argument advanced in Example 7 (see also Example 8) 
Let us symbolize the simple propositions used in Example 7 and 8 in the following way:

A: The physician should prescribe pills.

B: The symptoms will remain.

C: The physician should prescribe regular physical exercise.

D: The physician should prescribe doing mental exercise regularly.

E: The physician should prescribe a course in improvement of a new skill that the patient always wanted to learn.

F: The physician should prescribe coaching to diminish the patient's everyday stress.

With this symbolization, the argument schema for active criticism of unsound disjunctive syllogism, focus on the incomplete disjunctive premise, is presented in Figure 11, where the additional relevant information and the new relevant conclusions are written in brackets.

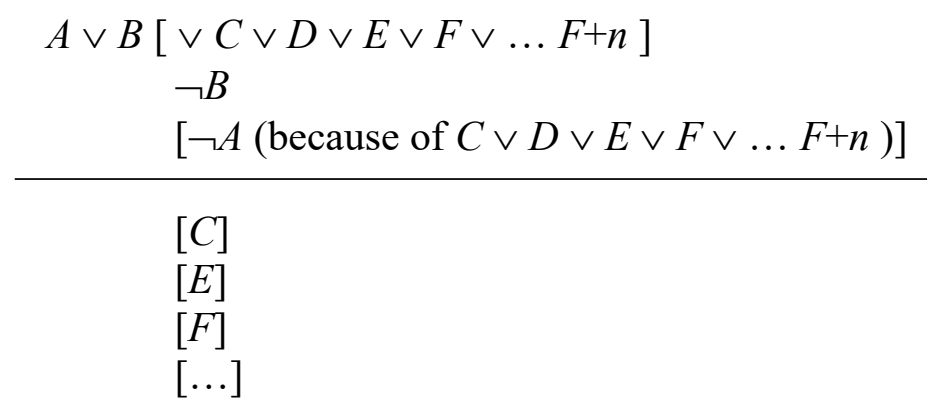

Figure 11: Active criticism for unsound disjunctive syllogism, focusing on the incomplete disjunctive premise

In using the propositional letters given above, we also obtain the general profile of dialogue for active criticism of unsound disjunctive syllogism, focusing on the incomplete disjunctive premise (Figure 12). 


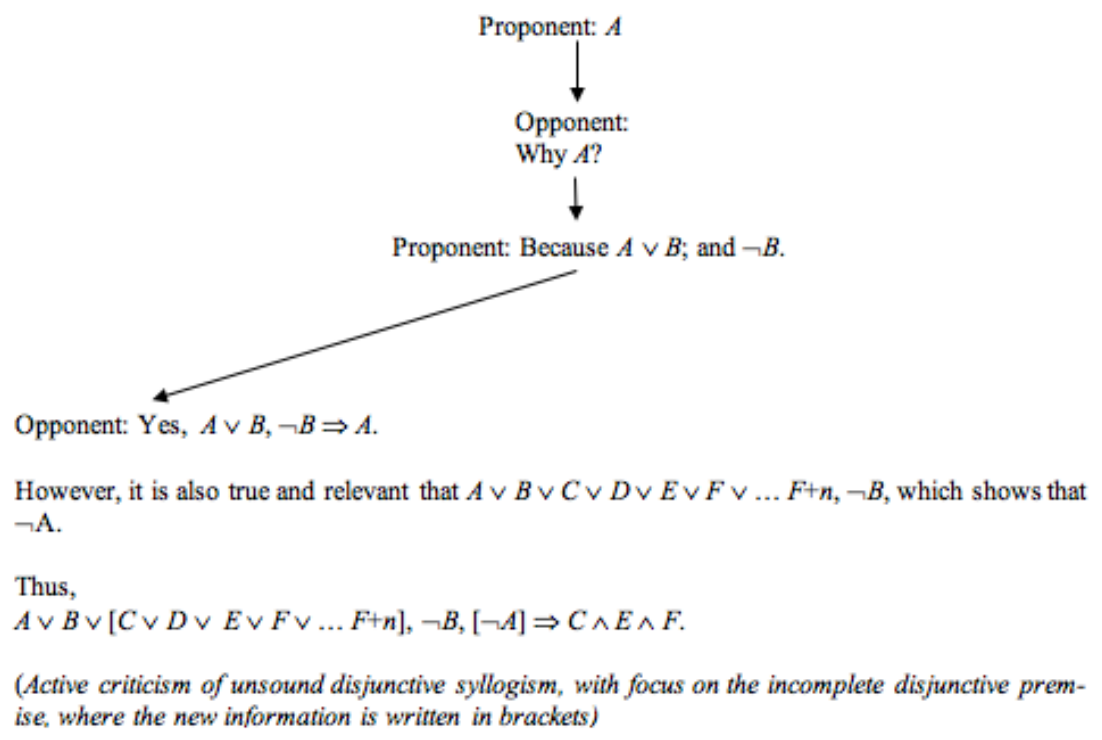

Figure 12: General structure of the profile of dialogue for active criticism of unsound disjunctive syllogism, focusing on the incomplete disjunctive premise

The types of false disjunctive syllogism and the related argument criticisms are summarized in Figure 13.

\section{Types of false disjunctive syllogism Corresponding argument criticism}

\begin{tabular}{|c|c|c|}
\hline \multicolumn{2}{|c|}{ Affirming a disjunct } & $\begin{array}{l}\text { Refuting by using inadmis- } \\
\text { sibility criticism }\end{array}$ \\
\hline \multicolumn{2}{|c|}{ Using an irrelevant disjunction } & $\begin{array}{l}\text { Questioning or refuting by } \\
\text { using irrelevance criticism }\end{array}$ \\
\hline $\begin{array}{l}\text { Unsound dis- } \\
\text { junctive syllo- } \\
\text { gism }\end{array}$ & $\begin{array}{l}\text { with the perspective that } \\
\text { emphasizes the falsity of } \\
\text { the disjuncts }\end{array}$ & $\begin{array}{l}\text { Questioning or refuting by } \\
\text { using tenability criticism }\end{array}$ \\
\hline & $\begin{array}{l}\text { with the perspective that } \\
\text { emphasizes the incom- } \\
\text { plete disjunctive premise }\end{array}$ & $\begin{array}{l}\text { Refuting by using active } \\
\text { criticism }\end{array}$ \\
\hline
\end{tabular}

Figure 13: Three types of false disjunctive syllogism and the corresponding argument criticisms 


\section{Similarities between false dilemma and false disjunctive syllogism}

One similarity between the two fallacies is that they have a disjunctive premise among their premises. Further, both fallacies use deductively valid argument schemas but still involve faulty argumentation. False dilemma explores the valid argument schemas of constructive and destructive dilemma (Figure 14), widely and rightly accepted as valid forms of inference in textbooks on formal logic. For instance, Copi et al. (2011, p. 320) rightly include simple constructive dilemma among the common argument forms; Kelley (1998, pp. 372-73; 2014, p. 318) and Pospesel and Lycan (2000, p. 108) correctly include constructive and destructive dilemmas in the standard rules of inference. As previously pointed out, false disjunctive syllogism explores the valid schemas of disjunctive syllogism (Figure 15).

\begin{tabular}{|c|c|c|c|}
\hline $\begin{array}{l}A \vee B \\
A \rightarrow C \\
B \rightarrow C\end{array}$ & $\begin{array}{l}A \vee B \\
A \rightarrow Q \\
B \rightarrow R\end{array}$ & $\begin{array}{l}E \rightarrow G \\
E \rightarrow H \\
\neg G \vee \neg H\end{array}$ & $\begin{array}{l}F \rightarrow J \\
K \rightarrow L \\
\neg J \vee \neg L\end{array}$ \\
\hline$C$ & $Q \vee R$ & $\neg E$ & $\neg F \vee \neg K$ \\
\hline $\begin{array}{l}\text { Simple Con- } \\
\text { structive Di- } \\
\text { lemma }\end{array}$ & $\begin{array}{l}\text { Complex Con- } \\
\text { structive Di- } \\
\text { lemma }\end{array}$ & $\begin{array}{l}\text { Simple De- } \\
\text { structive Di- } \\
\text { lemma }\end{array}$ & $\begin{array}{l}\text { Complex } \\
\text { Destructive } \\
\text { Dilemma }\end{array}$ \\
\hline
\end{tabular}

Figure 14: Valid argument schemas for constructive and destructive dilemma

\begin{tabular}{|c|c|c|c|}
\hline $\begin{array}{l}A \vee B \\
\neg A\end{array}$ & $\begin{array}{l}A \vee B \\
\neg B\end{array}$ & $\begin{array}{l}(A \vee B) \wedge \neg(A \wedge B) \\
A\end{array}$ & $\begin{array}{l}(A \vee B) \wedge \neg(A \wedge B) \\
\mathrm{B}\end{array}$ \\
\hline B & $A$ & $\neg B$ & $\neg A$ \\
\hline $\begin{array}{l}\text { Disjunctive } \\
\text { syllogism } \\
\text { with in- } \\
\text { cluding } \\
\text { disjunction }\end{array}$ & $\begin{array}{l}\text { Disjunctive } \\
\text { syllogism } \\
\text { with in- } \\
\text { cluding } \\
\text { disjunction }\end{array}$ & $\begin{array}{l}\text { Disjunctive syllogism } \\
\text { with excluding dis- } \\
\text { junction }\end{array}$ & $\begin{array}{l}\text { Disjunctive syllo- } \\
\text { gism with excluding } \\
\text { disjunction }\end{array}$ \\
\hline
\end{tabular}

Figure 15: Valid argument schemas for disjunctive syllogism (provided that there is relevance between $A$ and $B$ ) 
The ways in which the valid dilemma-arguments turn into the related types of false dilemmas are analyzed in detail in Tomić (2013). The same work also shows that the relevant literature is currently lacking other types of false dilemma than those systematized by Tomić. Below, the false dilemmas are presented that are sufficient for the analysis of the similarities and differences between false disjunctive syllogism and false dilemma (see Examples 9 and 10 and Section 6).

Another similarity is that in some of their variants, both false dilemma and false disjunctive syllogism, even though logically valid arguments, turn into faulty argumentation, due to the false disjuncts or incomplete information in the disjunctive premise. This is true for the unsound disjunctive syllogism (see section 3.3. in this article), as well as for simple and complex false quandary (two variants of false dilemma; see Example 9 and 10, and Tomić 2013, pp. 351-53). Both types of arguments appeal to soundness and not only to validity, which turns them into faulty argumentation, best approached by using tenability criticism or active criticism. Let us consider Example 9.

(P1) You talk to your boss about the unfair way in which he treats your colleague, or you avoid the discussion.

(P2) If you talk to your boss about the unfair way in which he treats your colleague, the boss will continue to treat the colleague unfairly (because you dared to talk about his bad behavior).

(P3) If you avoid the discussion, the boss will continue to treat your colleague unfairly (because nobody challenges that type of behavior).

(C) The boss will continue to treat your colleague unfairly.

\section{Example 9: The simple false quandary (a variant of false dilemma)}

As in the unsound disjunctive syllogism, the disjunctive premise in the valid argument of the simple false quandary is typically 
false/incomplete. In Example 9, (P1) is false because neither of the disjuncts is true: you can both not talk to your boss, and also not avoid the discussion. There is at least one additional option: you may talk to a person from the department of human resources and ask her to discuss with the boss his unfair behavior towards your colleague. This will, presumably, lead to his stopping that type of behavior because he will understand that people in charge have been informed of the behavior, which thus leads to a different conclusion than the one deduced in the original argument.

The similarity holds also for the complex false quandary (Tomić 2013, pp. 351-53), as illustrated by Example 10.

(P1) You talk to your boss about the unfair way in which he treats your colleague, or you avoid the discussion.

(P2) If you talk to your boss about the unfair way in which he treats your colleague, the boss will start to treat you in the same unfair way.

(P3) If you avoid the discussion, you will lose your friend's trust.

(C) The boss will start to treat you in the same unfair way, or you will lose your friend's trust.

\section{Example 10: The complex false quandary} (a variant of false dilemma)

In both the unsound disjunctive syllogism, and the valid argument of the complex false quandary the false/incomplete disjunctive premise leads to faulty argumentation. In Example 10, (P1) is false: you neither talk to your boss, nor the discussion is avoided. There is at least one additional option: you and your friend find another job, which leads to depriving the boss of the possibility of treating either one of you unfairly and you also keep your friend's trust. The conclusion of the first argument is thus refuted and a new conclusion is deduced from the augmented disjunctive premise. 


\section{Differences between false dilemma and false disjunctive syllogism}

The main difference is that the fallacies appeal to different argument schemas, which clearly demonstrates that they are different kinds of reasoning. As shown in Figure 14, the argument schemas used in the four types of false dilemma analyze the logical relation between a disjunctive claim and the consequents implied by each of the disjuncts, which then leads to a corresponding conclusion. In contrast, as shown in Figure 15, the argument schema appealed to in a false disjunctive syllogism analyzes the logical relation between the two mutually including disjuncts in relation to a situation in which one of them is negated (which leads to affirming the other in the conclusion); or the logical relation between the two mutually excluding disjuncts in relation to the situation when one of them is affirmed (which leads to negating the other disjunct in the conclusion). No analyses of the consequents implied from each of the disjuncts is at all involved in the argument schema of disjunctive syllogism.

Yet another difference is that false dilemma is always grounded in the truth-functionally valid argument of a constructive or destructive dilemma, whereas only two variants of false disjunctive syllogism are truth-functionally valid according to the schema of disjunctive syllogism. The third one, affirming a disjunct, seems to be valid due to the ambiguity between the including and excluding disjunction. On the other hand, the ambiguity between the including and excluding disjunction is completely irrelevant for false constructive dilemmas. In a simple constructive dilemma, it does not matter if the disjuncts exclude each other or not; if they imply the same consequents, the result would be the consequent that both of them imply. Equally for the complex constructive dilemma: if we know that one of the disjuncts implies a consequent different from the consequent that the other disjunct implies, the conclusion would be the disjunction between the consequents, no matter if the disjunction in the disjunctive premise of the dilemma argument is including or excluding. An additional difference between the fallacies is that relevance between disjuncts is crucial for one type of false disjunctive syllogism (using an irrelevant disjunction), but is not vital for any type of false dilemma. This makes relevance 
criticism adequate for one type of false disjunctive syllogism but is not required for any type of false dilemma.

The final difference consists in different strategies for the active criticism of defeasible false dilemma and, on the other hand, for the active criticism of the unsound disjunctive syllogism with focus on the incomplete disjunctive premise. Even if both types of arguments obscure the relevant information in the premises, they still obscure different information. Unsound disjunctive syllogism strongly focuses only on some selected possibilities in the disjunctive premise and thus obscures relevant information about additional disjunctive possibilities. The related active criticism adds the information about the additional disjuncts in the disjunctive premise, which refutes the initial argument in making obvious its unsoundness and brings in other possible conclusions (see Figures 10,11 and 12). In contrast, defeasible sound constructive dilemmas (which are variants of false dilemma) obscure relevant information about additional relevant consequents from the given disjuncts in the disjunctive premise (see columns 1 and 2 in Figure 16, where the additional information that the active criticism makes explicit is written in the brackets). Corresponding differences hold even regarding the active criticism of defeasible sound destructive dilemmas (see columns 3 and 4 in Figure 16, with the additional information made explicit by the active criticism written in brackets; for details about this type of active criticism see (Tomić 2013, pp. 356-64, 366).

\begin{tabular}{|c|c|c|c|}
\hline $\begin{array}{l}A \vee B \\
A \rightarrow C \\
B \rightarrow C \\
{[A \rightarrow D]} \\
{[B \rightarrow D]}\end{array}$ & $\begin{array}{l}A \vee B \\
A \rightarrow Q \\
B \rightarrow R \\
{[A \rightarrow Z]} \\
{[B \rightarrow W]}\end{array}$ & $\begin{array}{l}E \rightarrow G \\
E \rightarrow H \\
\neg G \vee \neg H \\
{[E \rightarrow M]} \\
{[E \rightarrow T]}\end{array}$ & $\begin{array}{l}F \rightarrow J \\
K \rightarrow L \\
\neg J \vee \neg L \\
{[F \vee K]}\end{array}$ \\
\hline $\begin{array}{l}C \\
{[D]} \\
\end{array}$ & $\begin{array}{l}Q \vee R \\
{[Z \vee W]}\end{array}$ & $\begin{array}{l}\neg E \\
{[E \rightarrow(M \wedge T)]}\end{array}$ & $\begin{array}{l}\neg F \vee \neg K \\
{[J \vee L]}\end{array}$ \\
\hline $\begin{array}{l}\text { Active criticism } \\
\text { of sound simple } \\
\text { constructive } \\
\text { dilemma }\end{array}$ & $\begin{array}{l}\text { Active criticism } \\
\text { of sound com- } \\
\text { plex constructive } \\
\text { dilemma }\end{array}$ & $\begin{array}{l}\text { Active criticism } \\
\text { of sound simple } \\
\text { destructive } \\
\text { dilemma }\end{array}$ & $\begin{array}{l}\text { Active criticism } \\
\text { of sound com- } \\
\text { plex destructive } \\
\text { dilemma }\end{array}$ \\
\hline
\end{tabular}

Figure 16: Argument schemas for active criticism of the four variants of defeasible sound dilemma (Tomić 2013) 


\section{Conclusion}

After providing an analysis and a definition of false disjunctive syllogism, the article has distinguished it clearly from false dilemma; this is summarized in Figure 17.

\begin{tabular}{|c|c|}
\hline Similarities & Differences \\
\hline $\begin{array}{l}\text { Both have a disjunctive } \\
\text { premise in their argument } \\
\text { schema. }\end{array}$ & $\begin{array}{l}\text { They explore different argument sche- } \\
\text { mas (and thus involve different types of } \\
\text { reasoning). }\end{array}$ \\
\hline $\begin{array}{l}\text { Both are (in all or in some } \\
\text { of their variants) grounded } \\
\text { in deductively valid argu- } \\
\text { ments/argument schemas, } \\
\text { but still involve faulty } \\
\text { argumentation. }\end{array}$ & $\begin{array}{l}\text { They require different strategies for } \\
\text { active criticism (which also shows their } \\
\text { different type of reasoning). } \\
\text { False dilemma is always grounded in a } \\
\text { logically valid argument (still with the } \\
\text { faulty argumentation), whereas false } \\
\text { disjunctive syllogism involves one } \\
\text { variant of truth-functionally non-valid } \\
\text { argument, and one variant of truth- } \\
\text { functionally, though not relevantly valid } \\
\text { argument. } \\
\text { Relevance between disjuncts is crucial } \\
\text { for one type of false disjunctive syllo- } \\
\text { gism, whereas it is not vital for any type } \\
\text { of false dilemma. } \\
\text { Relevance criticism is adequate for one } \\
\text { type of false disjunctive syllogism (using } \\
\text { an irrelevant disjunction), but is not } \\
\text { required for any type of false dilemma. }\end{array}$ \\
\hline
\end{tabular}

Figure 17: Similarities and differences between false dilemma and false disjunctive syllogism: a summary 
The following results of the article contribute to informal-logical studies of disjunctive fallacies:

- A definition of false disjunctive syllogism and its three types;

- guidelines for distinguishing between several types of one and the same fallacy (e.g. for making difference between several types of false disjunctive syllogism);

- guidelines for distinguishing between similar though different fallacies (e.g. for making difference between false disjunctive syllogism and false dilemma);

- insight that one and the same fallacy can manifest as both formal and informal fallacy;

- an application of the general strategies of argument criticism and profiles of dialogue to the related analyses of false disjunctive syllogisms;

- and a distinction between false dilemma and false disjunctive syllogism.

The results of the article may also be useful for human reasoning in general because they might strengthen the abilities of dealing with the two fallacies in related argumentative discourses. It would be valuable to undertake an empirical study to see if, and how, they do. It would also be cognitively important to undertake empirical studies about either-or and dilemma human reasoning to further improve the related informal-logical methods.

\section{References}

Anderson, Alan Ross and Nuel D. Jr. Belnap. 1975. Entailment:

The logic of relevance and necessity. Princeton and London: Princeton University Press.

Bhave, S. V. 1997. Situations in which disjunctive syllogism can 
lead from true premises to a false conclusion. Notre Dame journal of formal logic 38(3):398-405.

Bowell, Tracy and Gary Kemp. 2015. Critical thinking: A concise guide. London and New York: Routledge. 4th ed.

Cavender, Nancy and Howard Kahane. 2010. Logic and contemporary rhetoric: The use of reason in everyday life. Belmont, CA: Wadsworth Cengage Learning.

Copi, Irving M., Carl Cohen and K. D. McMahon. 2011. Introduction to logic. Boston: Prentice Hall. 14th ed.

Dugas, Michel J. and Melisa Robichaud. 2007. Cognitivebehavioral treatment for generalized anxiety disorder: From science to practice. New York: Routledge.

van Eemeren, Frans H. van and Rob Grootendorst. 1992. Argumentation, communication, and fallacies: A pragma-dialectical perspective. Hillsdale, NJ: L. Erlbaum.

Govier, Trudy. 2001. A practical study of argument. Belmont, CA: Wadsworth Thomson Learning.

Govier, Trudy. 2007. Two is a small number: False dichotomies revisited. In OSSA Conference Archive 57, URL: $<$ https://scholar.uwindsor.ca/ossaarchive/OSSA7/papersandcom mentaries/57>

Hamblin, Charles Leonard. 1970. Fallacies. London: Methuen.

Hansen, Hans V. 2020. Fallacies. Stanford encyclopedia of philosophy. ed. Edward N. Zalta. URL: <https://plato.stanford.edu>

Hansen, Hans V. and Robert C. Pinto. 1995. Fallacies: Classical and contemporary readings. University Park, Pa: Pennsylvania State University Press. 2nd edition ed.

Hansen, Hans V. and Cameron Fioret. 2016. A searchable bibliography of fallacies - 2016. Informal Logic. 36(4): 432-72.

Johnson, Ralph H. and J. Anthony Blair. 1994. Logical self defense. New York: McGraw-Hill. 2nd ed.

Kelley, David. 1998. The art of reasoning. NY: W.W. Norton.

Kelley, David. 2014. The art of reasoning: an introduction to logic and critical thinking. NY: W. W. Norton \& Company, Inc.

Krabbe, Erik C.W. 1992. So what? Profiles for relevance criticism in persuasion dialogues. Argumentation 6(2): 271-83.

Krabbe, Erik C.W. 1999. Profiles of dialogue. In JFAK: Essays Dedicated to Johan van Benthem on the occasion of his 50th 
birthday, Vol. III, eds. Jelle Gerbrandy, Maarten Marx, Maarten de Rijke and Yde Venema. Amsterdam: Amsterdam University Press. URL:

<http://www.illc.uva.nl/j50/contribs/krabbe/krabbe.pdf>

Lavers, Peter. 1988. Relevance and disjunctive syllogism. Notre Dame journal of formal logic. 29(1): 34-44.

Mortensen, C. 1983. The validity of disjunctive syllogism is not so easily proved. Notre Dame journal of formal logic. 24(1): 3540.

Pospesel, Howard and William G. Lycan. 2000. Introduction to logic: Propositional logic. Upper Saddle River, NJ: Prentice Hall.

Routley, Richard. 1984. Relevantism, material detachment, and the disjunctive syllogism argument. Canadian journal of philosophy. 14(2):167-88.

Schurz, Gerhard. 1991. Relevant deduction - from solving paradoxes towards a general theory. Erkenntnis. 35(1-3): 391-437.

Tindale, Christopher W. 2007. Fallacies and argument appraisal. NY: Cambridge University Press.

Tomić, Taeda. 2013. False dilemma: A systematic exposition. Argumentation. 27(4):347-68.

van Vleet, Jacob. 2010. Informal logical fallacies: A brief guide. Hamilton. 